\title{
Laryngeal mask versus facemask in the respiratory management during catheter ablation
}

\author{
Takashi Koyama ${ }^{1 *}$, Masanori Kobayashi', Tomohide Ichikawa', Yasushi Wakabayashi', Daiki Toma ${ }^{2}$ and \\ Hidetoshi Abe ${ }^{1}$
}

\begin{abstract}
Background: The purpose of this study is to investigate if a laryngeal mask could improve respiratory condition during radiofrequency catheter ablation (RFCA).

Methods: Twenty-four consecutive patients who underwent RFCA for atrial fibrillation were divided into two groups (Facemask group; $n=10$, Laryngeal mask group; $n=14$ ). All patients were completely sedated under intravenous anesthesia and fitted with artificial respirators during the RFCA. The capnography waveforms and their differential coefficients were analyzed to evaluate the changes of end-tidal $\mathrm{CO}_{2}\left(\mathrm{ETCO}_{2}\right)$ values, respiratory intervals, expiratory durations, and inspiratory durations.

Results: During the RFCA, ETCO 2 values of the laryngeal mask group were higher than those of the facemask group (36.0 vs. $29.2 \mathrm{mmHg}, p=0.005$ ). The respiratory interval was significantly longer in the laryngeal mask group than those in the facemask group ( $4.28 \mathrm{~s}$ vs.5.25 s, $p<0.001$ ). In both expiratory and inspiratory phases, the mean of the maximum and minimum values of $\mathrm{CO}_{2}$ was significantly higher when using a laryngeal mask than when using a facemask. The inspiratory-expiratory ratio of the laryngeal mask group was significantly larger than that of the facemask group (1.59 vs. 1.27, $p<0.001$ ). The total procedure duration, fluoroscopic duration and the ablation energy were significantly lower in the laryngeal mask group than in the facemask group. The $\mathrm{ETCO}_{2}$ value is the most influential parameter on the fluoroscopic duration during the RFCA procedure $(\beta=-0.477, p=0.029)$.
\end{abstract}

Conclusions: The use of a laryngeal mask could stabilize respiration during intravenous anesthesia, which could improve the efficiency of RFCA.

Keywords: Laryngeal mask, Catheter ablation, $\mathrm{ETCO}_{2}$, Capnography

\section{Background}

Radiofrequency catheter ablation (RFCA) is an effective therapeutic option for the treatment of atrial fibrillation (AF) [1]. Additionally, with the advancement of technologies such as $3 \mathrm{D}$ mapping, the success rate and safety of AF catheter ablation continues to increase. Catheter ablation for AF is a relatively long surgery and to avoid pain due to cauterization, it is commonly performed under intravenous anesthesia [2]. When an RFCA is performed under sedation by intravenous anesthesia,

\footnotetext{
* Correspondence: takashixkoyama@icloud.com

1 Department of Cardiovascular Medicine, Matsumoto Kyoritsu Hospital, Habaue 9-26, Matsumoto 390-8505, Japan

Full list of author information is available at the end of the article
}

breathing becomes unstable temporally and spatially due to obstruction of the upper airways. This situation causes problems such as: (1) decreased consistency between the geometry obtained from the 3D mapping and CT (2) decreased catheter static which causes difficult cauterization (3) drawing of air from the inserted sheath which increases the risk of air embolism [3]. To avoid such technical problems caused by respiratory instability associated with an RFCA, artificial respiration management is performed with a facemask [2] or a laryngeal mask. The invasiveness of respiration management using a laryngeal mask is midway between management using a facemask and that by tracheal intubation. When compared to tracheal intubation, the use of a laryngeal mask

(c) The Author(s). 2020 Open Access This article is distributed under the terms of the Creative Commons Attribution 4.0 International License (http://creativecommons.org/licenses/by/4.0/), which permits unrestricted use, distribution, and reproduction in any medium, provided you give appropriate credit to the original author(s) and the source, provide a link to the Creative Commons license, and indicate if changes were made. The Creative Commons Public Domain Dedication waiver (http://creativecommons.org/publicdomain/zero/1.0/) applies to the data made available in this article, unless otherwise stated. 
is lowly invasive, easy to operate, and has a low risk of pharyngeal and laryngeal injury $[4,5]$.

Capnography is used to continuously monitor ventilation to ensure that anesthesia is delivered safely [6]. Diseases and abnormalities related to breathing and circulation can be also be diagnosed quickly by analyzing capnography waveforms [7]. End-tidal $\mathrm{CO}_{2}\left(\mathrm{ETCO}_{2}\right)$ monitoring is extensively used as an objective parameter to determine whether appropriate ventilation is performed during operation.

There are only a few reports on the assessment and judgment of breathing conditions during an RFCA. Furthermore, the effects of the laryngeal mask in the respiratory management during RFCA have not been assessed extensively. Therefore, this study aimed to elucidate the differences between respiratory management using a laryngeal mask and a facemask and to demonstrate the beneficial effects of a laryngeal mask on the respiratory condition during an RFCA.

\section{Methods}

\section{Subjects and study design}

This study included 24 consecutive patients who underwent RFCA at our hospital for atrial fibrillation (paroxysmal, and persistent) from August 2018 to March 2019. We included patients who received pulmonary vein isolation without non-pulmonary vein (PV) ablation in this study. We excluded patients with left ventricular systolic function $\leq 50 \%$, respiratory diseases such as chronic obstructive pulmonary disease, dialysis, and patients who did not require sedation (such as paroxysmal supraventricular tachycardia). Patients who received cryoablation were also excluded as it requires diaphragmatic pacing and makes an accurate assessment of respiratory movement temporarily difficult.

Blood samples were collected from the peripheral vessels of 24 enrolled patients before they underwent ablation procedures. Additionally, the subjects were screened for severe inflammation, heart failure, anemia and renal failure before the ablation procedure. The values of brain natriuretic peptide (BNP) and C-reactive proteins (CRP) were converted to logarithms. Renal function was measured based on the estimated glomerular filtration rate (eGFR). The patients were screened for sleep apnea using a standard digital pulse oximeter (PULSOX-300 ${ }^{\mathrm{mm}}$, KONICA MINOLTA Inc.) before admission.

Two-dimensional, M-mode, and Doppler echocardiography (iE33; Philips Medical Systems, Andover, MA, USA) were performed to evaluate various parameters of heart functions in enrolled patients. The left ventricular ejection fraction was determined from an apical 4-chamber view using Simpson's method. Left atirum (LA) diameter was measured in the parasternal long axis view from trailing edge of the posterior aortic root-anterior LA complex to the posterior LA wall at end-systole.

Intravenous anesthesia was used for all the subjects and RFCA was performed under complete sedation. Assisted respiration was performed using an artificial respirator (VELA Type D, Vyaire Medical Inc.). The attending physician decided whether to use a facemask or a laryngeal mask for airway management. The settings for artificial respiration were: SIMV mode, ventilation frequency $=10$; pressure support $=6 \mathrm{cmH}_{2} \mathrm{O}$; and Positive End Expiratory Pressure $(\mathrm{PEEP})=5 \quad \mathrm{cmH}_{2} \mathrm{O}, \mathrm{FiO}_{2}=30-40 \%$. Informed consent regarding the catheter ablation procedure and the use of data was provided for all patients. The design, protocol, and handling of patient data were reviewed and approved by the Matsumoto Kyoritsu Hospital ethics committee (approval No.2019-004).

\section{Intravenous sedation during the catheter ablation procedure}

The patient was placed in a supine posture on the catheterization table. After confirming that there was nothing in the patient's mouth (such as dentures), hydroxyzine pamoate $(25 \mathrm{mg})$ was administered intravenously as premedication, and pentazocine $(15 \mathrm{mg})$ was similarly administered as a sedative. After $5 \mathrm{~min}$ the patient's vital signs and oxygen saturation levels were confirmed to be within normal limits. An Ambu-Bag (SPUR $1 \mathrm{l}^{\mathrm{m}}$, Ambu Inc. Denmark) and face mask (Disposable Face Mask, Vital signs Inc. USA.) with an oxygen flow rate of $10 \mathrm{~L} / \mathrm{min}$ was gently placed on the patient's nose and mouth followed by intravenous administration of propofol at $0.5 \mathrm{mg} / \mathrm{kg} / 10 \mathrm{~s}$ until the patient fell asleep. After confirming that the olfactory hair reflex had disappeared, the patient's head was placed in the Magill position, the mandible was lowered manually, and the mouth was opened. A medical lubricating gel was applied and a laryngeal mask (i-gel ${ }^{\mathrm{Tm}}$ : Intersurgical Ltd., UK) was slowly inserted. A laryngeal mask appropriate for the patient's weight and physical constitution was selected and an Ambu-Bag was placed over the laryngeal mask. The bag was gently compressed to raise the chest, and after confirming that breathing sounds could be heard, the artificial respirator was attached. Insertion of the sheath and administration of dexmedetomidine hydrochloride was done simultaneously at $6 \mu \mathrm{g} / \mathrm{kg} / \mathrm{h}$ by continuous intravenous drip infusion over $10 \mathrm{~min}$ (initial bolus). Next, according to the patient's condition, a maintenance dose at $0.2-0.7 \mu \mathrm{g} / \mathrm{kg} / \mathrm{h}$ (maintenance bolus) was administered to reach the optimum intravenous level. The olfactory hair reflex was confirmed every $20 \mathrm{~min}$ and if present, propofol was administered intravenously at $0.5 \mathrm{mg} / \mathrm{kg} / 10 \mathrm{~s}$ until the reflex disappeared. During the RFCA, if the patient moved due to pain, propofol was again administered intravenously. 
During the RFCA, the right internal jugular and right femoral veins were catheterized and a sheath was inserted in the femoral artery to monitor blood pressure. After a transseptal puncture using intracardiac echocardiography, a circular mapping catheter (Lasso, Biosense Webster Inc., Diamond Bar, CA, USA) was placed on the ostium of each PV atrium. The PV isolation was performed with a $3.5-\mathrm{mm}$ tip, open-irrigated ablation catheter (THERMOCOOL ${ }^{\mathrm{Tm}}$, Biosense Webster Inc. USA, or TACTICATH $^{\mathrm{mm}}$ Abbot Inc. USA) to achieve electric isolation of the PV potential. All ablation procedures were performed with a $3 \mathrm{D}$ electroanatomical mapping system $\left(\right.$ CARTO $^{\mathrm{m}}$, Biosense Webster Inc. USA, or Ensite Navix $^{\mathrm{m}}$, Abbot Inc. USA). The RF energy output was titrated to $25-35 \mathrm{~W}$ at a flow rate of $17-30 \mathrm{ml} / \mathrm{min}$, with a maximum temperature of $42^{\circ} \mathrm{C}$. Three fluoroscopic angles (RAO view $30^{\circ}$, RAO view $0^{\circ}$, LAO view $50^{\circ}$ ) were used to confirm the catheter position. The endpoint of the PV isolation was the creation of a bidirectional conduction block from the atrium to the pulmonary veins and vice versa. At least $20 \mathrm{~min}$ after a successful PV isolation, adenosine triphosphate was administered using intravenous isoproterenol $(1-3 \mu \mathrm{g} / \mathrm{kg} / \mathrm{min})$ to provoke a reconnection of the PVs (dormant PV conduction). If any dormant PV conduction was observed, additional RF energy was applied at the earliest PV activation site until the dormant PV conduction was eliminated. If the AF was inducible after these procedures, sinus rhythm was restored by transthoracic cardioversion. During the procedure, bolus and additional heparin were administered to maintain an activated clotting time of $300-350 \mathrm{~s}$. The blood pressure of the patient was continuously monitored, and $\mathrm{SpO}_{2}$, 12-lead electrocardiogram and $\mathrm{ETCO}_{2}$ measurements were taken during the ablation procedure. The duration of artificial respiration was defined as the total duration of the procedure. Total fluoroscopy duration, duration of radiofrequency energy, delivered radiofrequency energy, and total ablation points during the ablation procedure were calculated.

\section{Evaluation of the accuracy of the $\mathrm{ETCO}_{2}$ monitoring device}

First, we analyzed the correlation between $\mathrm{pCO}_{2}$ obtained from blood gas tests and $\mathrm{ETCO}_{2}$ obtained from capnography in 9 patients subjected to blood gas tests during RFCA. A linear correlation was seen between the 2 tests $\left(\mathrm{Y}=0.8531 * \mathrm{X}+4.888, \mathrm{R}^{2}=0.8808, p\right.$ value $\left.=0.0002\right)$. As a strong correlation was seen between the 2 tests, it is confirmed that measuring $\mathrm{ETCO}_{2}$ levels is appropriate for evaluating blood levels of carbon dioxide. Figure $1 \mathrm{a}, \mathrm{b}$ shows the capnography waveforms obtained during measuring $\mathrm{CO}_{2}$. Generally, expiratory phase is from the point

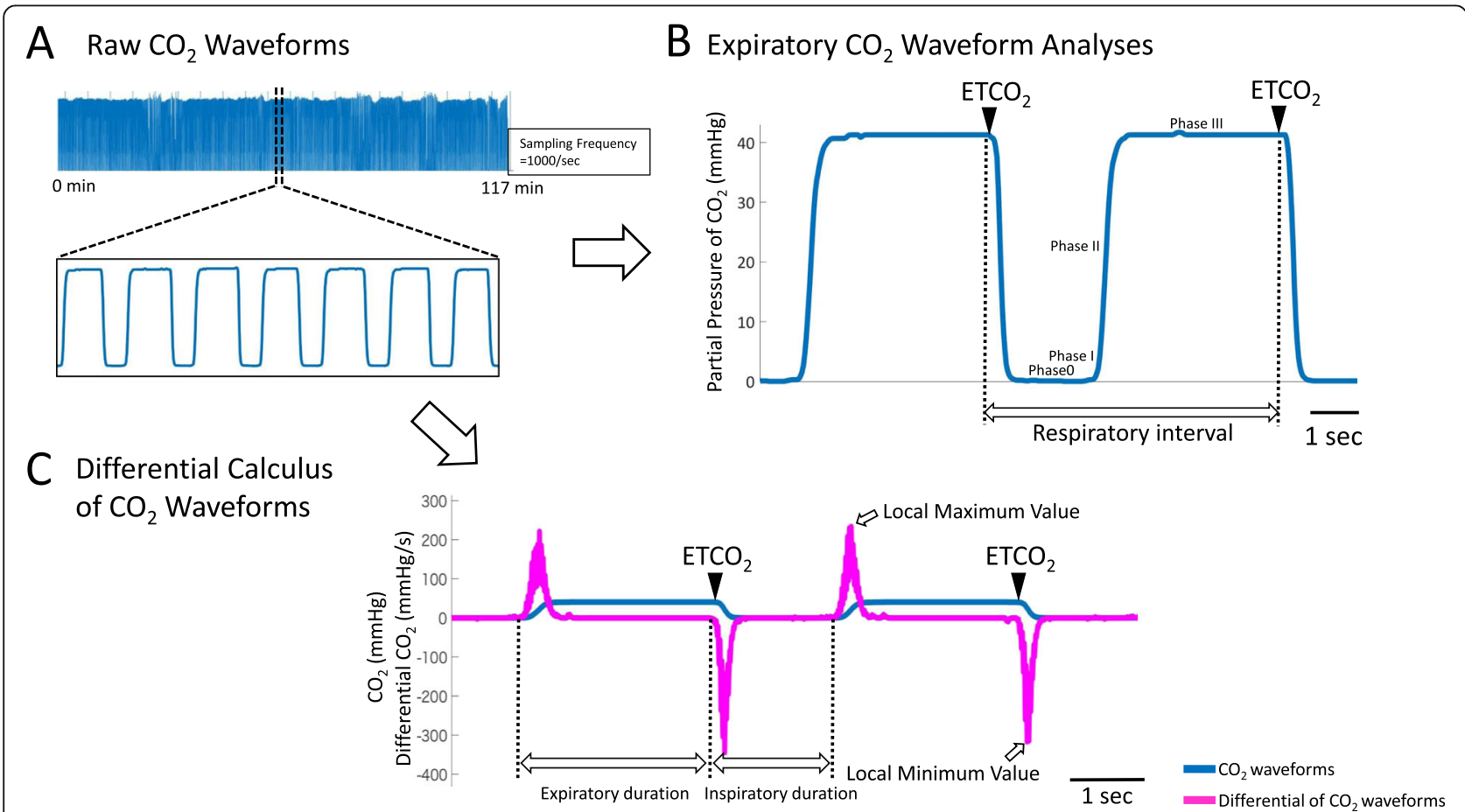

Fig. $1 \mathbf{a}$ and $\mathbf{b}$ Representative capnography waveforms obtained from an enrolled patient in this study. The expiratory phase was divided into 0 , $\mathrm{I}, \mathrm{II}$, and III phases. The respiratory interval is defined by the distance between adjacent points of end-tidal $\mathrm{CO}_{2}\left(\mathrm{ETCO}_{2}\right)$. The interval between adjacent $\mathrm{ETCO}_{2}$ values is defined as respiratory interval. c: Representative capnography waveforms (blue lines) and their differential $\mathrm{CO}_{2} \mathrm{Curves}$ (magenta lines) obtained from an enrolled patient in this study. The differential $\mathrm{CO}_{2}$ curve was constructed, and the local maximum and minimum values were calculated where the respiratory intervals, and expiratory and inspiratory durations could be easily identified and calculated 


\section{A. A patient with laryngeal mask}
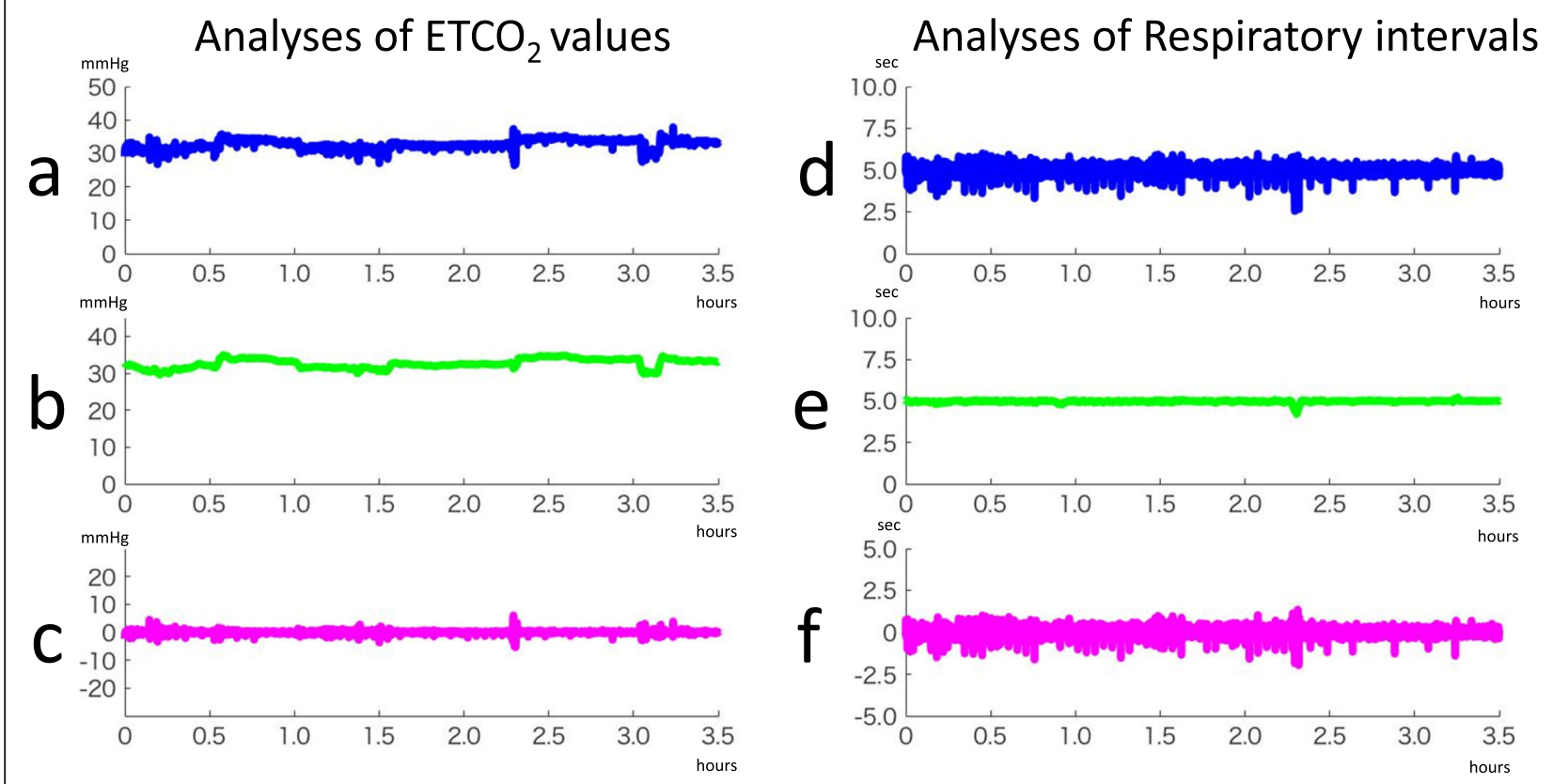

B. A patient with facemask

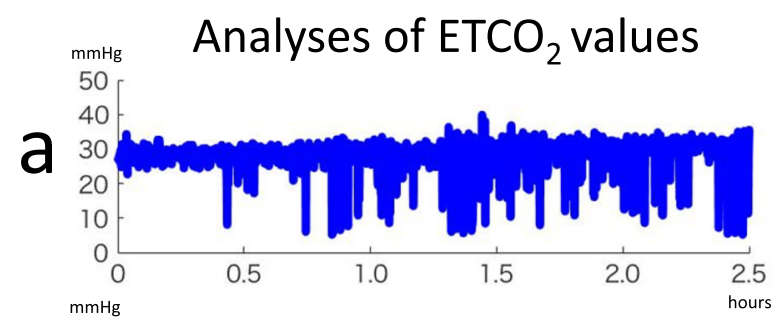

${ }_{\text {sec }}$ Analyses of Respiratory intervals
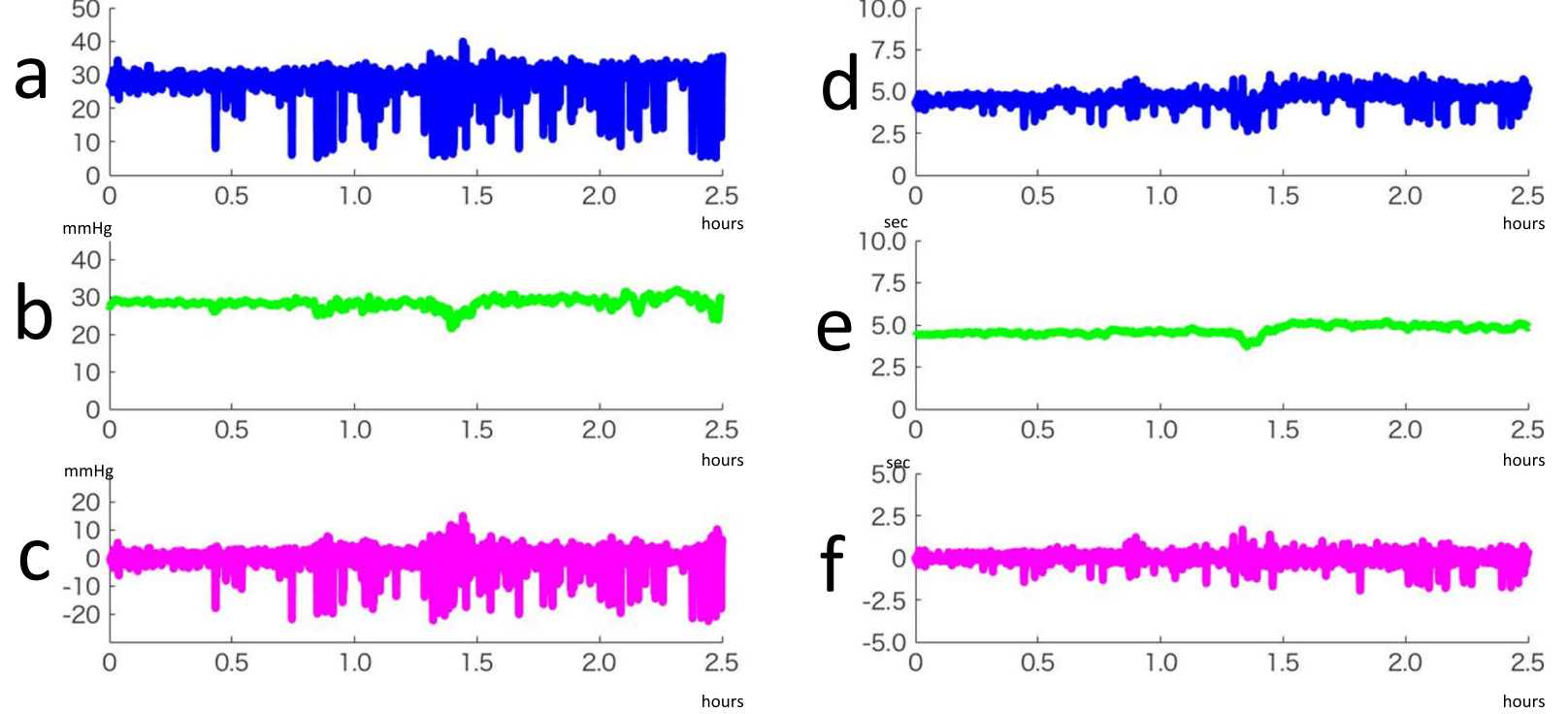

Fig. 2 (See legend on next page.) 
(See figure on previous page.)

Fig. 2 Representative results of chronological analyses of end-tidal $\mathrm{CO}_{2}\left(\mathrm{ETCO}_{2}\right)$ and respiratory intervals in a patient using a laryngeal mask. A. A patients with laryngeal mask. a and d: chronological changes of $\mathrm{ETCO}_{2}$ and respiratory intervals. b and e: moving averages of $\mathrm{ETCO}_{2}$ and respiratory intervals. $\mathrm{C}$ and f: chronological changes of standard deviations of $\mathrm{ETCO}_{2}$ and respiratory intervals. B. A patients with facemask. Representative results of chronological analyses of end-tidal $\mathrm{CO}_{2}\left(\mathrm{ETCO}_{2}\right)$ and respiratory intervals in a patient using a facemask. a and d: chronological changes of ETCO ${ }_{2}$ and respiratory intervals. $\mathrm{b}$ and e: moving averages of $\mathrm{ETCO}_{2}$ and respiratory intervals. $\mathrm{c}$ and f: chronological changes of standard deviations of $\mathrm{ETCO}_{2}$ and respiratory intervals

when the capnography starts increasing to the point that is defined as $\mathrm{ETCO}_{2}$, while the inspiratory phase lasts from the point that is defined as $\mathrm{ETCO}_{2}$ to the start of the expiratory phase. The expiratory phase was further divided into 0, I, II, and III phases (Fig. 1b). Next, the differential $\mathrm{CO}_{2}$ waveforms was constructed (Fig. 1c, magenta lines), and the local maximum values (maximum values) and local minimum values (minimum values) were calculated, where the respiratory intervals, expiratory durations and inspiratory could be easily identified and calculated. In this study, the analysis of respiratory parameters was performed as shown in Fig. 1c. A gas monitor (OLG-3800" Nihon Kohden Co. Ltd., Japan) was used to monitor $\mathrm{CO}_{2}$.

\section{Data acquisition and analyses}

After the patient was completely sedated, assisted respiration (using a mechanical ventilator) and continuous recording of $\mathrm{CO}_{2}$ (using an expiratory $\mathrm{CO}_{2}$ gas monitor) were started. The $\mathrm{CO}_{2}$ data from the expiratory gas monitor were transferred to a biological signal recorder (PowerLab 26T $\mathrm{T}^{\mathrm{Tm}}$; AD Instruments, Colorado Springs, CO, USA), which consisted of an A/D computer and another computer installed with a signal acquisition/analysis software (Chart Pro $5^{\mathrm{rw}}$; AD Instruments). The sampling rate was set at $1 \mathrm{kHz}$ and was recorded as matrix data. The matrix data per patient was $9.46 \times$ $10^{6} \pm 2.59 \times 10^{6}$. The analyzed $\mathrm{ETCO}_{2}$ samples per patient were $1555.3 \pm 671.6$ points. In order to identify the temporal changes in $\mathrm{ETCO}_{2}$, the local $\mathrm{ETCO}_{2}$ peaks of the $\mathrm{CO}_{2}$ waveform during the RFCA was identified, and to eliminate noise, the frequency between the peaks was set to $\leq 0.16 \mathrm{~Hz}$ and peaks greater than $0.5 \mathrm{~Hz}$ were excluded. Only the peak data were extracted and arranged in chronological order (Fig. 2A-a, B-a), and the central

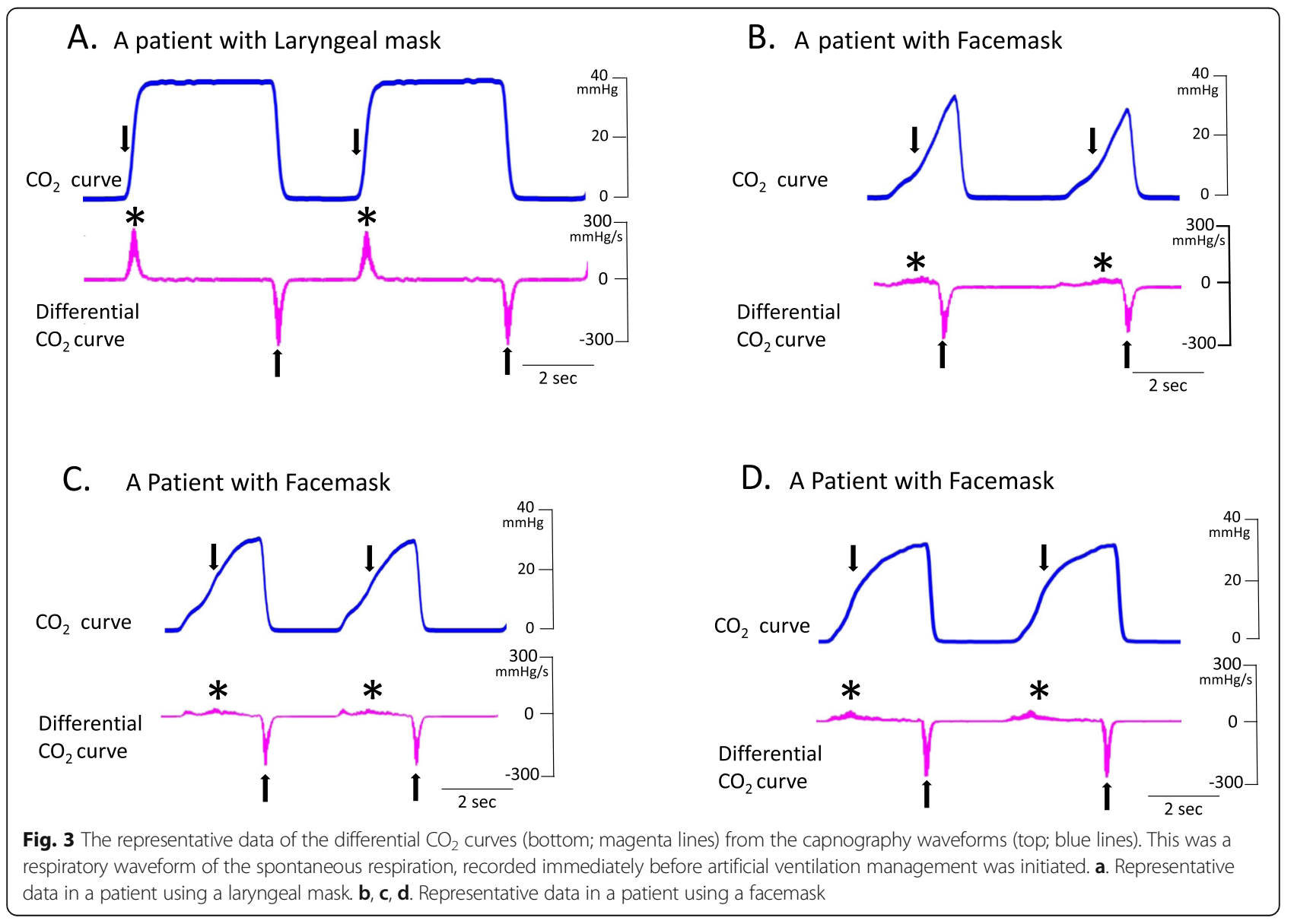


moving average of 20 points was recorded (Fig. 2A-b, Bb). The difference in the moving average from the peak $\mathrm{ETCO}_{2}$ sequence was calculated and the changes in standard deviation over time were plotted (Fig. 2A-c, Bc) to calculate the mean standard deviation. The differential coefficient per $0.001 \mathrm{~s}$ was calculated from the matrix data obtained from the biological signal recording device and a graph of the differential coefficient was constructed by arranging it in chronological order (Fig. 3: magenta lines). The respiratory interval was calculated by the peak-peak interval on the $\mathrm{ETCO}_{2}$ values of the $\mathrm{CO}_{2}$ curve (Fig. 2A-d, B-d), and the central moving average of 20 points was calculated (Fig. 2A-e, B-e). By calculating the difference in the sequence of the moving average from the sequence of the respiratory interval, the standard deviation of the data in chronological order was calculated (Fig. 2A-f, B-f). The differential coefficient curve during RFCA was constructed and the mean of the maximum increasing velocity of $\mathrm{CO}_{2}$ partial pressure during expiration and its standard deviation were calculated by identifying the peak on the positive side of the graph. By constructing the central moving averages at 500-800 points on the differential coefficient curve, the data was smoothened. The smoothened differential coefficient was defined as the expiratory time (from the point, where differential coefficients changes from negative to positive, to the point, where changes from positive to negative), and all the respiratory intervals were analyzed by calculating the mean and standard deviation. The peak on the negative side of the differential coefficient curve was set as the maximum lowering velocity of $\mathrm{CO}_{2}$ partial pressure during inspiration (Fig. 3: magenta lines) and its mean and standard deviation were calculated. Similarly, the central moving average was calculated and the time for the differential coefficient to turn from negative to positive was set as the inspiratory time. The sum of the expiratory and inspiratory durations was defined as the respiratory interval. It was confirmed that the error between the respiratory interval, which calculated using the sum of the expiratory and using the $\mathrm{ETCO}_{2}$ peaks was $\leq 0.05 \mathrm{~s}$.

\section{Statistical analyses}

All data were represented as mean \pm standard deviation or percentage. When comparing the 2 groups, normally distributed parameters were analyzed using the t-test, and parameters without a normal distribution were analyzed using the Wilcoxon test. A linear analysis was used to examine the correlation between the 2 parameters and was represented with a partial correlation coefficient, significance probability, and a 95\% confidence interval (CI). A multivariate analysis was performed on parameters with a significance probability $<0.1$, which were analyzed by univariate analysis. All statistical analysis was performed using the SPSS $19.0 \mathrm{~J}$ software for Windows. The significance level was set at $<0.05$.

\section{Results}

Table 1 presents the background of the subjects included in this study. There was no variable (age, sex ratio, body mass index, medical history, echocardiography data, laboratory data, types of atrial fibrillation, 3\% obstructive desaturation index, and the dose of drugs regarding the intravenous anesthesia) that showed a significant difference between the facemask and the laryngeal mask groups. Additionally, the dose of dexmedtomidine hydrochloride and propofol were not different between two groups.

Figure 2 presents the representative data of the changes of $\mathrm{ETCO}_{2}$ values (Fig. 2A a-c) and that of respiratory interval (Fig. $2 \mathrm{~A} \mathrm{~d}-\mathrm{f}$ ) in chronological order of the patients who used the laryngeal mask. Figure 2A-a shows the temporal changes in $\mathrm{ETCO}_{2},-\mathrm{b}$, the moving average, and $-\mathrm{c}$, the difference (standard deviation: $\mathrm{SD}$ )

Table 1 Baseline characteristics of enrolled patients with catheter ablation

\begin{tabular}{|c|c|c|c|}
\hline Variable & $\begin{array}{l}\text { Facemask } \\
\text { group }(n=10)\end{array}$ & $\begin{array}{l}\text { Laryngeal mask } \\
\text { group }(n=14)\end{array}$ & $p$ value \\
\hline Age, years & $67.9 \pm 9.8$ & $66.7 \pm 9.6$ & 0.771 \\
\hline Male sex, n (\%) & $6(60)$ & $10(71.4)$ & 0.559 \\
\hline $\mathrm{BMI}, \mathrm{kg} / \mathrm{m}^{2}$ & $23.1 \pm 2.4$ & $24.0 \pm 3.1$ & 0.425 \\
\hline Hypertension, n (\%) & $4(40)$ & $7(50)$ & 0.697 \\
\hline Diabetes mellitus, n (\%) & $1(10)$ & $3(21.4)$ & 0.615 \\
\hline Dyslipidemia, n (\%) & $1(10)$ & $2(14.3)$ & 0.759 \\
\hline \multicolumn{4}{|l|}{ Echocardiography data } \\
\hline LA diameter (mm) & $40.2 \pm 6.3$ & $36.1 \pm 6.2$ & 0.131 \\
\hline Ejection fraction (\%) & $67.9 \pm 12.3$ & $68.0 \pm 7.3$ & 0.981 \\
\hline \multicolumn{4}{|l|}{ Laboratory data } \\
\hline eGFR (ml/min/kg) & $58.9 \pm 13.2$ & $58.8 \pm 10.9$ & 0.989 \\
\hline Ln BNP (pg/ml) & $4.3 \pm 1.2$ & $4.1 \pm 0.6$ & 0.560 \\
\hline $\begin{array}{l}\text { Ln C-reactive protein } \\
(\mathrm{mg} / \mathrm{ml})\end{array}$ & $-2.7 \pm 0.8$ & $-2.3 \pm 1.2$ & 0.324 \\
\hline Hemoglobin (g/dl) & $14.2 \pm 1.1$ & $14.2 \pm 1.9$ & 0.977 \\
\hline \multicolumn{4}{|l|}{ Types of atrial fibrillation } \\
\hline Paroxysmal atrial fibrillation & $6(60)$ & $8(57.1)$ & 0.889 \\
\hline Persistent atrial fibrillation & $4(40)$ & $6(42.9)$ & 0.895 \\
\hline $3 \%$ ODI (n/h) & $18.1 \pm 12.1$ & $17.7 \pm 14.7$ & 0.958 \\
\hline $\begin{array}{l}\text { Analyzed } \mathrm{ETCO}_{2} \\
\text { samples (points/a patient) }\end{array}$ & $1722.3 \pm 682.0$ & $1435.9 \pm 662.7$ & 0.314 \\
\hline $\begin{array}{l}\text { Dose of Dexmedetomidine } \\
\text { Hydrochloride }(\mu \mathrm{g} / \mathrm{kg})\end{array}$ & $2.7 \pm 0.5$ & $2.3 \pm 0.6$ & 0.103 \\
\hline Dose of Propofol (mg/kg) & $1.6 \pm 0.6$ & $1.9 \pm 0.7$ & 0.244 \\
\hline
\end{tabular}

The values are reported as the mean \pm standard deviation. $B M I$ Body mass index, $L A$ Left atrium, eGFR estimated gromerular filtration rate, BNP Brain natriuretic peptide, $\mathrm{ODI}$ Obstructive desaturation index, $E T C \mathrm{O}_{2}$ End-tidal $\mathrm{CO}_{2}$ 
between -a and -b. The moving average of $\mathrm{ETCO}_{2}$ progressed without any notable variation $\left(\right.$ mean $\mathrm{ETCO}_{2}=$ $32.5 \mathrm{mmHg}$ ) and variation per respiration was also relatively low $(\mathrm{SD}=1.12 \mathrm{mmHg}$ ). Figure $2 \mathrm{~A}$-d presents the changes over time in respiratory interval, $-\mathrm{e}$, the moving average, and $-\mathrm{f}$, the standard deviation. As with the changes in $\mathrm{ETCO}_{2}$, respiratory interval also progressed with no perioperative variation $(\mathrm{SD}=0.63$ s). Additionally, as shown in Fig. $2 \mathrm{~B}, \mathrm{ETCO}_{2}$ progressed at low values for patients used a facemask, (Fig. 2B-b; mean $\mathrm{ETCO}_{2}=28.3 \mathrm{mmHg}$ ), and the variation in $\mathrm{ETCO}_{2}$ values was large (Fig. 2B-c; $\mathrm{SD}=4.25$ $\mathrm{mmHg}$ ). Compared to the patients who used a laryngeal mask, the respiratory interval of the patients who used a facemask was mildly short (Fig. 2B-e; mean respiratory interval $=4.93 \mathrm{~s}$ ), and the standard deviations were the same (Fig. 2B-f; $\mathrm{SD}=0.82 \mathrm{~s}$ ). Figure 3 shows the representative data of the differential $\mathrm{CO}_{2}$ curve (bottom; magenta lines) from the capnography waveforms (top; blue lines). This was a respiratory waveform of the spontaneous respiration recorded immediately before artificial ventilation management was initiated. In the $\mathrm{CO}_{2}$ curve (blue lines), phase II rises sharply in patients that used a laryngeal mask (Fig. 3a; down arrow), while in those that used a facemask, it rose gently (Fig. 3b-d; down arrow). Moreover, in patients that used a facemask, there were cases where phase II was convex at the top (Fig. 3b) and convex at the bottom (Fig. 3c and d). Analysis of the differential $\mathrm{CO}_{2}$ curve revealed that the peak of the velocity of rise of phase II in patients that used a laryngeal mask was high at approximately $300 \mathrm{mmHg}$ / sec, while that of the patients that used a facemask was low at approximately $30 \mathrm{mmHg} / \mathrm{sec}$ (asterisks), respectively. The lowering velocity of the $\mathrm{CO}_{2}$ curve during inspiration was slightly higher in patients that used a laryngeal mask than that in those who used a facemask. Next, the respiratory parameters were compared between the 2 groups during RFCA (Fig. 4). The mean $\mathrm{ETCO}_{2}$ was significantly higher in the laryngeal mask group (36.1 vs. $29.2 \mathrm{mmHg}, p=0.0023$, Fig. $4 a)$ than that in the facemask group, and the SD was significantly lower in the laryngeal mask group (2.3 vs. $3.9 \mathrm{mmHg}, \quad p=0.0178$, Fig. $4 \mathrm{e})$. The

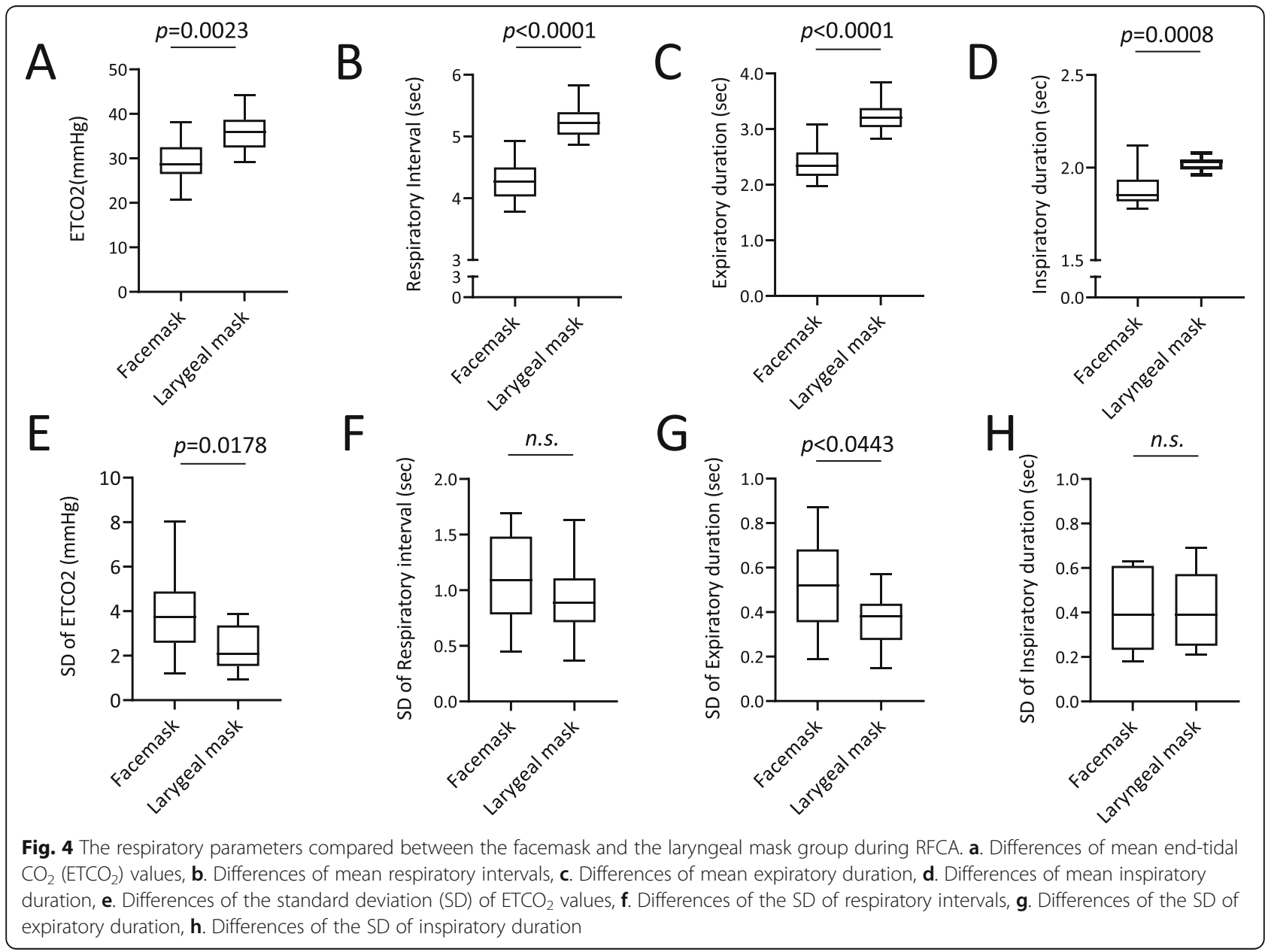


respiratory interval was significantly lower in patients who used a facemask than that in those who used a laryngeal mask (4.282 vs. $5.247 \mathrm{~s}, p<0.0001$, Fig. $4 \mathrm{~b}$ ). Additionally, there was no difference between the 2 groups regarding the SD for the respiratory interval (Fig. 4f). The expiratory duration was significantly longer (3.223 vs. $2.397 \mathrm{~s}, p<0.0001$, Fig. 4c) and the SD significantly shorter $(0.361$ vs. $0.513 \mathrm{~s}, p<0.0443$, Fig. 4g) in the laryngeal mask group than those in the facemask group. The inspiratory duration was significantly longer in the laryngeal mask group than that in the facemask group (2.024 vs. $1.885 \mathrm{~s}, p=$ 0.0008 , Fig. 4d), and the SD for inspiratory duration showed no significant difference (Fig. 4h). The maximum values in the expiratory and the minimum values in the inspiratory phases were identified from the waveforms obtained from the $\mathrm{CO}_{2}$ differential waveforms (asterisks or arrows of magenta lines, Fig. 3 ), and the mean for these are shown in Fig. 5. In the expiratory phase, the maximum values of the laryngeal mask group were significantly higher than that of the facemask group (198.1 vs. $78.8 \mathrm{mmHg} / \mathrm{sec}$, $p=0.0024$, Fig. 5a); however, there was no difference in the standard deviations (Fig. 5b). Conversely, in the inspiratory phase, the minimum value in the laryngeal mask group was significantly higher than that in the facemask group $(-392.4$ vs. $-293.5 \mathrm{mmHg} / \mathrm{sec}, \quad p=$ 0.0019 , Fig. 5c). Furthermore, the SD of the laryngeal mask group was significantly lower ( -57.1 vs. -78.0 $\mathrm{mmHg} / \mathrm{sec}, p=0.0214$, Fig. $5 \mathrm{~d}$ ). Figure $6 \mathrm{a}$ and $\mathrm{b}$ present the respective plots of the facemask and laryngeal mask groups with the SD of the respiratory interval set on the horizontal axis and that of $\mathrm{ETCO}_{2}$ on the longitudinal axis. In the laryngeal mask group, the SD of the respiratory interval and that of $\mathrm{ETCO}_{2}$ showed a strong positive correlation $\left(R^{2}=0.7252, p=\right.$ 0.0001 , Fig. $6 \mathrm{~b})$. Although a positive correlation was seen in the facemask group, there was more variation in the sample $\left(R^{2}=0.3881, p=0.0444\right)$. Figure 6e shows the comparison of the slope obtained from the linear regression lines of Fig. $6 a$ and $b$. The slope of the linear regression line was lower in the laryngeal mask group than in the facemask group. Additionally, there was no correlation between respiratory interval and $\mathrm{ETCO}_{2}$ for both groups (Fig. $6 \mathrm{c}$ and d). Figure 7 shows the relationship between expiratory and inspiratory durations for both groups. In the laryngeal mask group, the mean expiratory duration was 3.223 $\mathrm{s}$, and mean inspiratory duration was $2.024 \mathrm{~s}$ (Fig. 7b). Additionally, in the facemask group, the mean

\section{Expiratory phase}

A

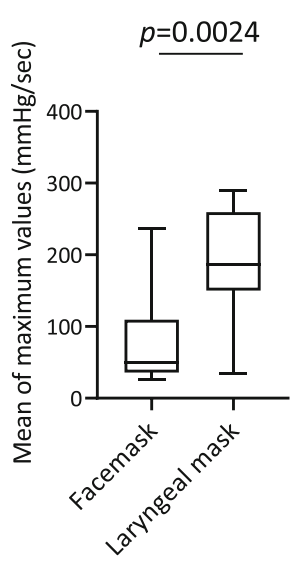

B

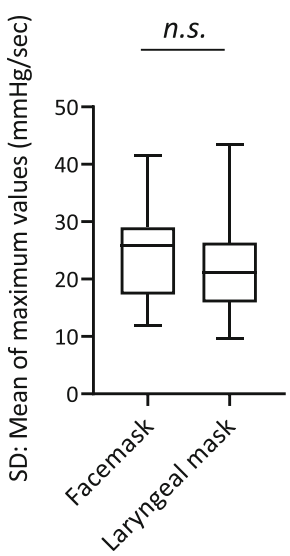

\section{Inspiratory phase}

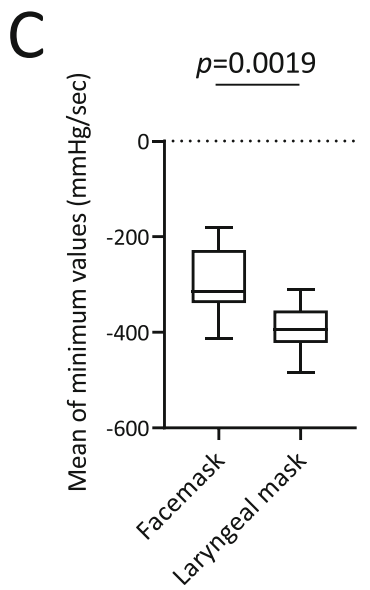

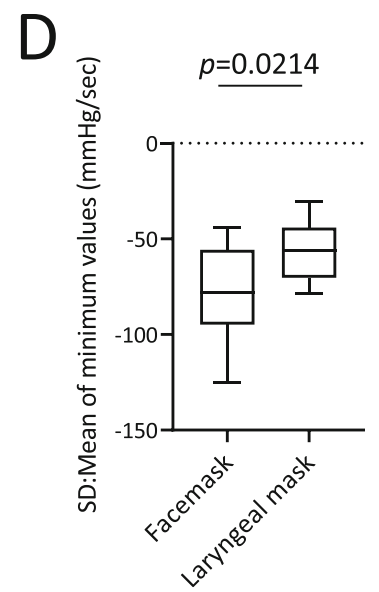

Fig. 5 The maximum and minimum values and these standard deviations (SD), which were identified from the $\mathrm{CO}_{2}$ differential waveforms. a. Differences of mean of maximum values in the expiratory phase, $\mathbf{b}$. Differences of the SD of maximum values in the expiratory phase, $\mathbf{c}$. Differences of mean of minimum values in the inspiratory phase, $\mathbf{d}$. Differences of the SD of minimum values in the inspiratory phase 


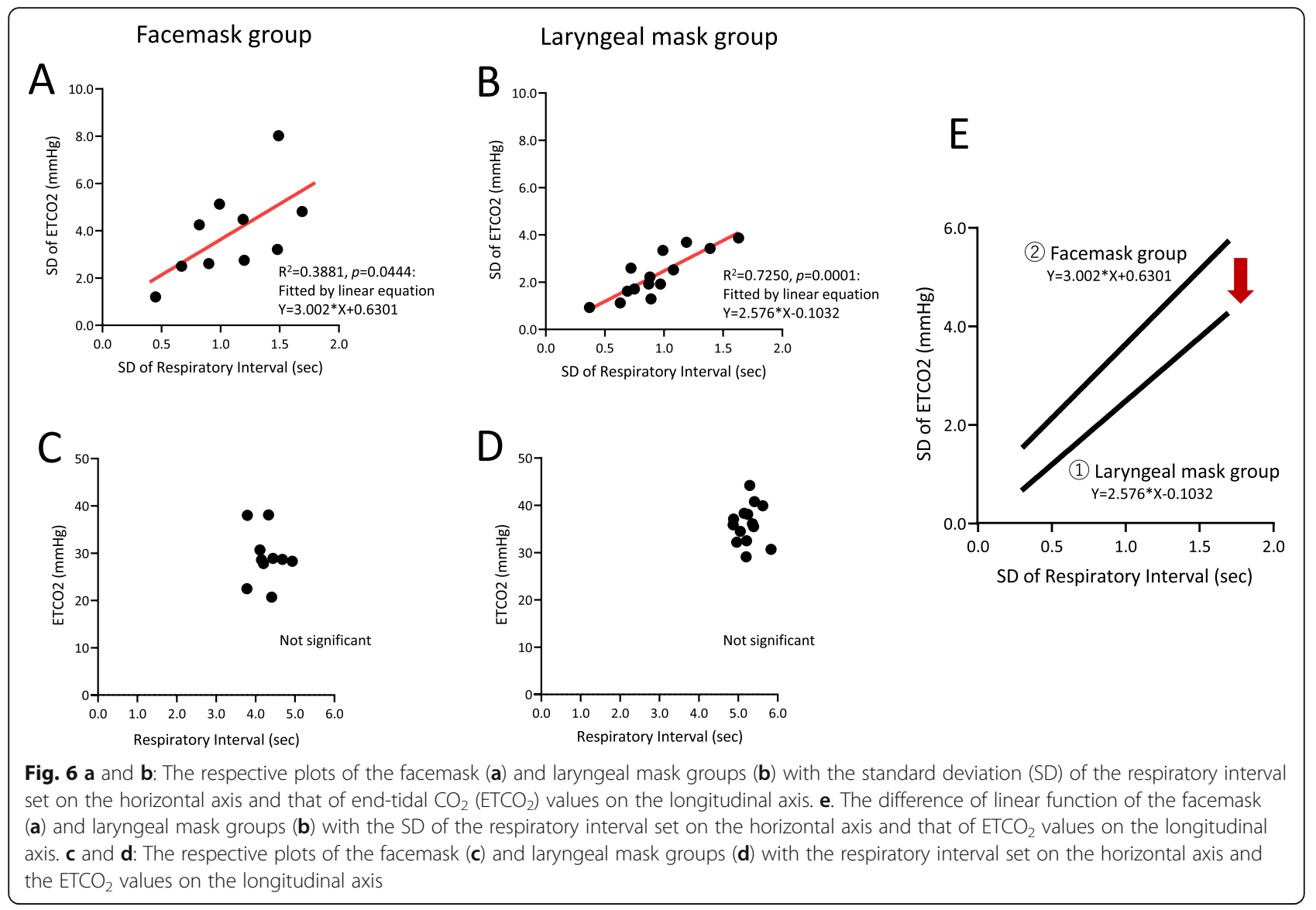

expiratory duration was $2.397 \mathrm{~s}$, and mean inspiratory duration was $1.885 \mathrm{~s}$ (Fig. 7c). The analysis of the mean of the inspiratory-expiratory (I/E) ratio showed that the ratio in the laryngeal mask group was 1:1.592 and that in the facemask group was 1:1.272, showing a prolonged expiratory duration in the laryngeal mask group (Fig. 7a). The use of a laryngeal mask resulted in a larger variation in the expiratory duration than that in the inspiratory duration. Table 2 shows the results of the RFCA, including total ablation procedures, the duration of the fluoroscopic procedure, total ablation points, and the delivered ablation energy. Multivariate analyses, including the use of a laryngeal mask, the $\mathrm{ETCO}_{2}$ value, and $\mathrm{I} / \mathrm{E}$ ratio, showed that the $\mathrm{ETCO}_{2}$ value was the most influential parameter for the duration of the fluoroscopic procedure during the RFCA (Table 3).

\section{Discussion}

From this study, the following conclusions were drawn. 1) During the RFCA, the $\mathrm{ETCO}_{2}$ value of the laryngeal mask group was higher than that of the facemask group; the SD of the $\mathrm{ETCO}_{2}$ value was low. 2) The respiratory interval, expiratory duration, and inspiratory duration were significantly longer in the laryngeal mask group than those in the facemask group; the SD of the expiratory duration was significantly shorter. 3) In the expiratory phase, the mean value of the maximum increasing velocity of $\mathrm{CO}_{2}$ partial pressure was significantly higher when using a laryngeal mask than when using a facemask. The mean value of the maximum lowering velocity in the inspiratory phase was significantly high, and the SD was also high. 4) In both groups, a significant correlation was found between the SDs of the respiratory interval and $\mathrm{ETCO}_{2}$. The slope of the linear regression line was higher in the facemask group than in the laryngeal mask group. 5) The I/E ratio of the laryngeal mask group was significantly larger than that of the facemask group. 6) The $\mathrm{ETCO}_{2}$ value has the most influence on the fluoroscopy procedure duration during the RFCA.

The duration of an RFCA procedure is relatively long time to perform and is commonly performed under sedation with intravenous anesthesia to avoid pain caused by cauterization. However, during the procedure, respiration becomes unstable in terms of time and space, and stable respiratory management becomes necessary. Compared with tracheal intubation, airway management by a laryngeal mask has 


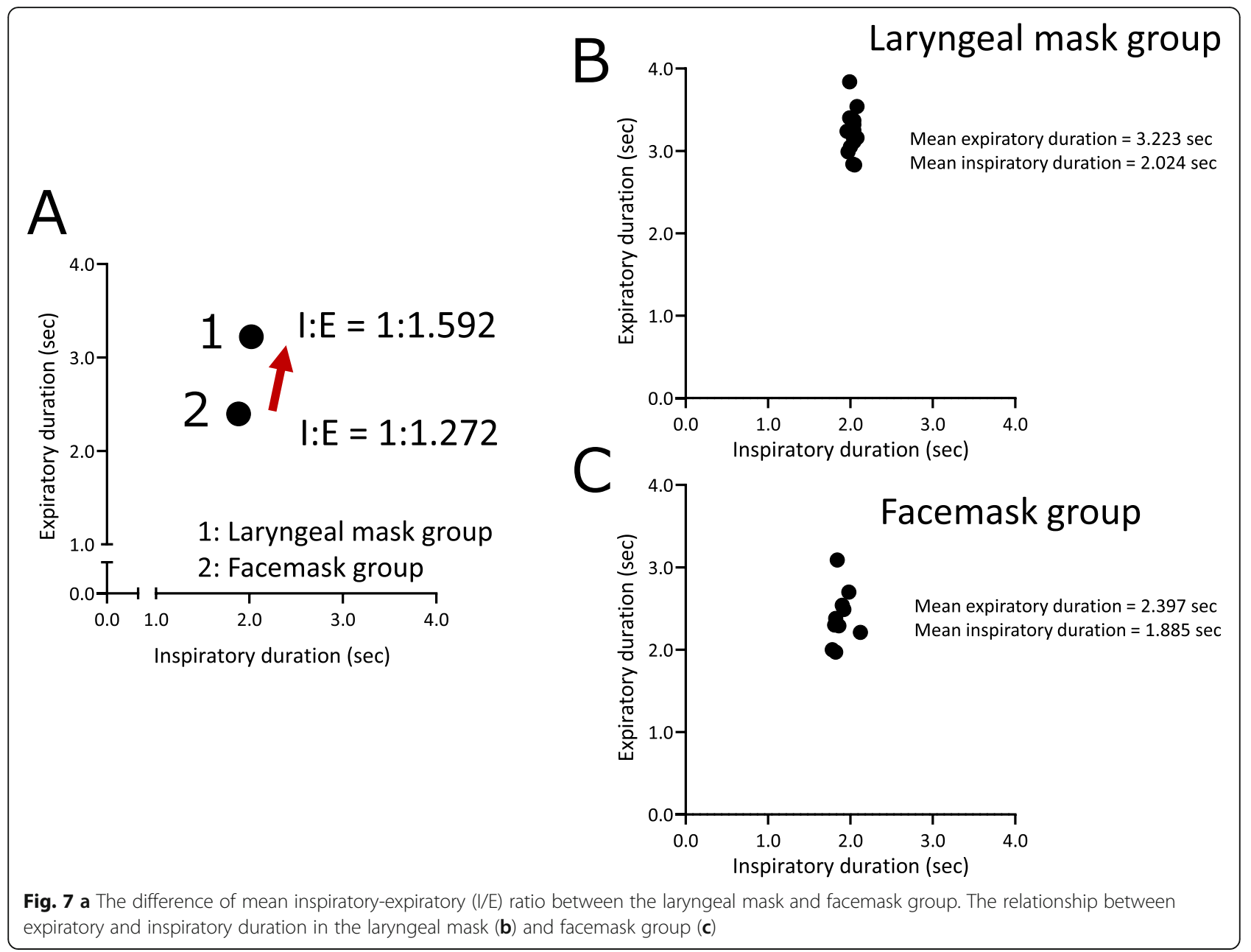

the advantages of lower invasiveness, easier insertion, and lower risk for injury to the pharynx and larynx [2]. Recently, various kinds of laryngeal masks could be used in the clinical practice according to patient's peculiarity [8]. However, the use of laryngeal masks, compared with that of facemasks, has not been investigated extensively.

Sedation during the catheter ablation causes the upper airways to relax. This phenomenon, combined with gravity, causes some reactions: 1) the soft palate comes in close contact with the pharynx, resulting in impaired nasal breathing; 2) the base of the tongue drops causing obstruction in the upper airways; and 3) the epiglottis falls on the glottis obstructing the airways. The use of a laryngeal mask allows the airways to be secured even if there is obstruction due to the soft palate and sinking of the base of the tongue. Additionally, a laryngeal mask could prevent the obstruction of the airways by moving the epiglottis anteriorly [9]. When compared with a laryngeal mask, a facemask does not ensure direct patency of the airways; therefore, when a positive pressure is exerted by mechanical ventilation, adequately securing

Table 2 Ablation data in enrolled patients with catheter ablation

\begin{tabular}{llll}
\hline Variable & Facemask group $(n=10)$ & Laryngeal mask group $(n=14)$ & $p$ value \\
\hline Total duration of procedure, $\min$ & $194.5 \pm 29.1$ & $162.5 \pm 39.1$ & 0.037 \\
Total fluoroscopic duration, $\min$ & $82.9 \pm 17.6$ & $55.9 \pm 18.5$ & 0.002 \\
Duration of RF energy, $\min$ & $40.3 \pm 7.6$ & $32.8 \pm 9.0$ & 0.042 \\
Delivered RF energy, $\left(\times 10^{3} \mathrm{~J}\right)$ & $73.5 \pm 16.2$ & $58.1 \pm 16.1$ & 0.030 \\
Total ablation points, (points) & $86.2 \pm 14.0$ & $64.6 \pm 23.7$ & 0.017 \\
\hline
\end{tabular}

The values are reported as the mean \pm standard deviation RF Radiofrequency 
Table 3 Uni- and multivariate analyses of influential factors on the fluoroscopic duration

\begin{tabular}{|c|c|c|c|c|c|c|}
\hline \multirow[t]{2}{*}{ Variable } & \multicolumn{3}{|c|}{ Univariate analysis } & \multicolumn{3}{|c|}{ Multivariate analysis } \\
\hline & $\bar{\beta}$ & $95 \% \mathrm{Cl}$ & $\overline{p \text { value }}$ & $\bar{\beta}$ & $95 \% \mathrm{Cl}$ & $p$ value \\
\hline The use of laryngeal mask & -0.608 & $-42.55,-11.39$ & 0.002 & & & \\
\hline $\mathrm{ETCO}_{2}$ value & -0.718 & $-3.954,-1.583$ & $<0.001$ & -0.477 & $-3.717,-0.228$ & 0.029 \\
\hline I/E ratio & -0.368 & $-78.30,4.287$ & 0.077 & & & \\
\hline Respiratory interval & -0.538 & $-35.50,-6.438$ & 0.007 & & & \\
\hline
\end{tabular}

$\beta$ Partial correlation coefficient, $\mathrm{Cl}$ confidence interval, $\mathrm{ETCO}_{2}$ end-tidal $\mathrm{CO}_{2}$;

The upper data are adjusted by age and gender

the pharyngeal part of the airways may be difficult in some cases [10]. In this study, both decreases in mean $\mathrm{ETCO}_{2}$ concentration and variations in $\mathrm{ETCO}_{2}$ concentration were shown in the facemask group (Fig. 4a and e). Additionally, both expiratory flow velocity and expiratory duration decreased in the facemask group as shown in Figs. 3, 4c, and 5a. This may have been a result of physical occlusion and stenosis of the upper airways, which caused expiratory instability. This study showed that variations (spatial variations) were seen in the amount of $\mathrm{CO}_{2}$ elimination due to stenosis of the airways. However, onset of variations (temporal variations) in the respiratory interval, which were frequently observed in patients with heart failure, were not experienced in patients with intravenous anesthesia (Fig. 4f).

As previously mentioned, inadequate expiratory ability and variation of the expiratory duration (Fig. 4g) could be caused by obstructions in the upper airways of patients with facemasks. Inadequate expulsion of $\mathrm{CO}_{2}$ due to obstructions in the upper airways could increase the $\mathrm{CO}_{2}$ concentration in blood and cause hyperventilation, which decreases the respiratory interval, expiratory duration, and inspiratory duration (Fig. 4b, c, d). Compared with the patients that used a facemask, those that used a laryngeal mask had a longer expiratory duration $(2.397 \mathrm{~s}$ vs. $3.223 \mathrm{~s}$ ) and a longer inspiratory duration (1.885 s vs. $2.024 \mathrm{~s}$ ) (Fig. 7b and c). In both groups, the inspiratory duration could be secured at the minimum limit via the SIMV mode and pressure support of the mechanical ventilator. This resulted in a smaller decrease in the inspiratory duration than that in the expiratory duration (Fig. 4d). Additionally, mechanical ventilator support could not produce the SD of inspiratory duration in both groups (Fig. 4h). These results indicate that the laryngeal mask relieves obstructions in the upper airways, ensures adequate expiratory duration, adequate inspiratory duration, and prevents hyperventilation, resulting in respiratory stabilization (Fig. 4c) in patients under intravenous sedation.

The differential coefficients of the $\mathrm{CO}_{2}$ waveforms could be examined to evaluate the airflow velocities in the expiratory and inspiratory phases (Figs. 3 and 5). The capnography waveforms can clarify various abnormalities in respiratory conditions [11, 12]. For patients using laryngeal masks, the shape of the capnogram waveform per respiratory cycle resembled a square, while for those using facemasks, the shape resembled a triangle. The maximum value (maximum $\mathrm{CO}_{2}$ increasing velocity) of the $\mathrm{CO}_{2}$ concentration in the expiratory phase was distinctly higher in the laryngeal mask group, when compared with that of the facemask group, indicating that the use of laryngeal masks promotes patency of the airways and smooth expiration (Fig. 3: Asterisk and Fig. 5a). The minimal value (maximum $\mathrm{CO}_{2}$ lowering velocity) of the $\mathrm{CO}_{2}$ concentration in the inspiratory phase was also higher in the laryngeal mask group than in the facemask group, indicating that the inspiratory phase could also benefit from effective management of the upper airways (Fig. 5c). Additionally, the variations of the minimum value in the inspiratory phase were higher in the facemask group than in the laryngeal mask group. These variations were likely caused by the mechanical ventilator, which was set to a minimum of 10 air changes in the SIMV mode and a positive pressure supply of $6 \mathrm{cmH}_{2} \mathrm{O}$ in the pressure support mode, and selfinspiration (Fig. 5d). The settings of the mechanical ventilation in the expiratory phase did not differ between two groups. Moreover, the ventilator setting did not change for each expiratory phase. These situations did not produce the differences in the variation of the maximum value in the expiratory phase between the two groups (Fig. 5b). The results of this study suggest that inadequate airway management decreased the maximum and minimum values of $\mathrm{CO}_{2}$ concentration, resulting in inadequate $\mathrm{CO}_{2}$ expulsion. These situations could lead to hyperventilation or decreased respiratory intervals during the RFCA procedure.

As shown in Fig. 6a, b, and e, when the variation in the respiratory interval is taken from the horizontal axis and the variation in $\mathrm{ETCO}_{2}$ from the longitudinal axis, the correlation coefficient becomes 1 unit larger. This result implies that the variation in $\mathrm{CO}_{2}$ expulsion ability during expiration is larger than the variation in the respiratory rhythm under intravenous anesthesia. Moreover, inadequate airway management techniques are characterized by further intensification of changes in 
$\mathrm{ETCO}_{2}$ values more than the variations in the respiratory interval. Variation in respiratory rhythm is commonly seen in heart failure patients, and is caused by a delay in circulation and increased sensitivity towards the medullary hydrogen ion $[13,14]$. There were only a few heart failure patients in this study. Thus even if the $\mathrm{CO}_{2}$ partial pressure increased, abnormal respiratory rhythm occurred relatively less. As shown in Fig. 6a, b and e, the use of a laryngeal mask could secure the airways, resulting in increased $\mathrm{CO}_{2}$ expulsion ability, thus reducing the slope of the correlation coefficient (Fig. 6e, red arrow). This ability of the laryngeal mask causes $\mathrm{CO}_{2}$ concentration in blood to decrease, resulting in stable respiration.

Figure 7 shows the differences in the expirationinspiration balance between the two groups. The I/E ratio of the patients that used laryngeal masks was 1:1.592 whereas it was 1:1.272 for those that used facemasks. Additionally, the inspiratory duration was longer in the laryngeal mask group when compared with the facemask group. These results clarify that the stabilization of respiration during RFCA was caused by a longer expiratory duration rather than inspiratory duration (Fig. 7a, red arrow). Preserving stable respiration is important while performing the ablation procedure. An increase in respiratory rate and variations in respiratory depth could worsen the fixation of the catheter during ablation, resulting in uneven cauterization and longer procedure duration. As a result of inadequate respiratory management, the success rate of ablation may decrease or other complications and disadvantages may arise during the RFCA procedure. Actually, total procedure and fluoroscopic durations were longer, and total RF energy and ablation points were higher in the facemask group than in the laryngeal mask (Table 2). Moreover, the $\mathrm{ETCO}_{2}$ value was the strongest parameter for the fluoroscopic duration during the RFCA procedure (Table 3). Therefore, the establishment of a stable ablation procedure using some respiratory devices, such as laryngeal masks, is required.

The limitations of this study were: 1) this was not a randomized study, 2) the number of subjects were comparatively fewer and the study was performed in a single institution, and 3) the success rates in the acute and chronic phases were not evaluated. 4) some objective monitoring methodology, such as bispectral index, to evaluate the depth of anesthesia could not be used. A large-scale in-depth study involving the RFCA success rate needs to be performed to establish the efficacy of the laryngeal mask.

\section{Conclusion}

The use of a laryngeal mask could stabilize respiration during intravenous anesthesia, which could improve the efficiency of RFCA.

\section{Abbreviations}

AF: Atrial fibrillation; BNP: Brain natriuretic peptide; Cl: Confidence interval; CRP: C-reactive proteins; eGFR: estimated glomerular filtration rate;

$\mathrm{ETCO}_{2}$ : End-tidal $\mathrm{CO}_{2}$; I/E ratio: Inspiratory/expiratory ratio; LA: Left atrium; PEEP: Positive end expiratory pressure; PV: Pulmonary vein;

RFCA: Radiofrequency catheter ablation; SD: Standard deviation

\section{Acknowledgements \\ The authors thank the catheter operating room staff of the Matsumoto Kyoritsu Hospital for their help in this study.}

\section{Authors' contributions}

TK obtained ethics approval, collected data and analyzed data through the mathematical approach. TK also drafted the manuscript and review it. MK helped the statistical analyses. TI, YW and HA conceived of the study and revised manuscript. DT advised the method of application regarding the laryngeal mask. All authors read and approved the final manuscript.

\section{Funding}

There was no funding obtained for this study.

\section{Availability of data and materials}

The datasets used and analyzed during the current study are available from the corresponding author on reasonable request.

\section{Ethics approval and consent to participate}

Written informed consent regarding the catheter ablation procedure and the use of data was provided for all patients. The design, protocol, and handling of patient data were reviewed and approved by the Matsumoto Kyoritsu Hospital ethics committee (approval No.2019-004)

\section{Consent for publication}

Not applicable.

\section{Competing interests}

The authors declare that they have no competing interests.

\section{Author details}

${ }^{1}$ Department of Cardiovascular Medicine, Matsumoto Kyoritsu Hospital, Habaue 9-26, Matsumoto 390-8505, Japan. ²Department of

Gasteroenterological Surgery, Matsumoto Kyoritsu Hospital, Matsumoto, Japan.

Received: 5 November 2019 Accepted: 27 December 2019

Published online: 07 January 2020

\section{References}

1. Koyama T, Tada H, Sekiguchi Y, Arimoto T, Yamasaki H, Kuroki K, et al. Prevention of atrial fibrillation recurrence with corticosteroids after radiofrequency catheter ablation: a randomized controlled trial. J Am Coll Cardiol. 2010;56(18):1463-72.

2. Yamaguchi T, Shimakawa Y, Mitsumizo S, Fukui A, Kawano Y, Otsubo T, et al. Feasibility of total intravenous anesthesia by cardiologists with the support of anesthesiologists during catheter ablation of atrial fibrillation. J Cardiol. 2018;72(1):19-25

3. Kuwahara T, Takahashi A, Takahashi Y, Kobori A, Miyazaki S, Takei A, et al. Clinical characteristics of massive air embolism complicating left atrial ablation of atrial fibrillation: lessons from five cases. Europace. 2012;14(2): 204-8.

4. Amer GF, Abdeldayem OT, Lahloub FMF. Effect of local anesthesia and general anesthesia using I-gel laryngeal mask airway in diabetic patients undergoing cataract surgery: comparative study. Anesth Essays Res. 2019; 13(2):209-13.

5. Sorbello M, Afshari A, De Hert S. Device or target? A paradigm shift in airway management with implications for guidelines, clinical practice and teaching. Eur J Anaesthesiol. 2018:35(11):811-4.

6. Vakil E, Sarkiss M, Ost D, Vial MR, Casal RF, Eapen GA, et al. Safety of monitored anesthesia care using Propofol-based sedation for Pleuroscopy. Respiration. 2018;95(1):1-7.

7. Conway A, Collins P, Chang K, Mafeld S, Sutherland J, Fingleton J. Sequence analysis of capnography waveform abnormalities during nurse-administered 
procedural sedation and analgesia in the cardiac catheterization laboratory. Sci Rep. 2019;9(1):10214.

8. Sorbello M, Petrini F. Supraglottic airway devices: the search for the best insertion technique or the time to change our point of view? Turk J Anaesthesiol Reanim. 2017;45(2):76-82.

9. Qamarul Hoda M, Samad K, Ullah H. ProSeal versus Classic laryngeal mask airway (LMA) for positive pressure ventilation in adults undergoing elective surgery. Cochrane Database Syst Rev. 2017;20(7):CD009026.

10. Firme EB, Cavalcanti IL, Barrucand L, Assad AR, Figueiredo NV. Curative ablation of atrial fibrillation: comparison between deep sedation and general anesthesia. Rev Col Bras Cir. 2012;39(6):462-8.

11. Cracco O, Degrugilliers L, Rames C, Bécourt A, Bayat $S$. Change in capnogram waveform is associated with bronchodilator response and asthma control in children. Pediatr Pulmonol. 2019;54(6):698-705.

12. Ruiz de Gauna S, Leturiondo M, Gutiérrez JJ, Ruiz JM, González-Otero DM, Russell JK, et al. Enhancement of capnogram waveform in the presence of chest compression artefact during cardiopulmonary resuscitation. Resuscitation. 2018;133:53-8.

13. Takagawa J, Asanoi H, Tobushi T, Kumagai N, Kadokami T, Dohi K, et al. PROST investigators. Multicenter, prospective study on respiratory stability during recovery from deterioration of chronic heart failure. Circ J. 2018:83(1):164-73

14. Koyama T, Kobayashi M, Ichikawa T, Wakabayashi T, Abe H. An application of pacemaker respiratory monitoring system for the prediction of heart failure. Respir Med Case Rep. 2019;26:273-5.

\section{Publisher's Note}

Springer Nature remains neutral with regard to jurisdictional claims in published maps and institutional affiliations.

- fast, convenient online submission

- thorough peer review by experienced researchers in your field

- rapid publication on acceptance

- support for research data, including large and complex data types

- gold Open Access which fosters wider collaboration and increased citations

- maximum visibility for your research: over $100 \mathrm{M}$ website views per year

At $\mathrm{BMC}$, research is always in progress.

Learn more biomedcentral.com/submissions 